\title{
Relation of lung function, maximal inspiratory pressure, dyspnoea, and quality of life with exercise capacity in patients with chronic obstructive pulmonary disease
}

\author{
P J Wijkstra, E M TenVergert, Th W van der Mark, D S Postma, R Van Altena, \\ J Kraan, G H Koëter
}

Rehabilitation Centre, Beatrixoord Hospital, 9751 ND Haren (Groningen), The Netherlands P J Wijkstra R Van Altena

Office for Medical Technology Assessment University Hospital, Groningen, The Netherlands E M TenVergert

Department of Pulmonary Diseases, University Hospital, Groningen, The Thetherlands $\mathrm{W}$ van der Mark D S Postma J Kraan

G H Koëter

Reprint requests to: Dr P J Wijkstra.

Received 2 November 1993 Returned to authors 31 December 1993 Revised version received 24 January 1994 Accepted for publication 26 January 1994

\begin{abstract}
Background - Several studies have shown that both objective and subjective measurements are related to exercise capacity in patients with chronic obstructive pulmonary disease (COPD). In this study the relative contribution of lung function, maximal inspiratory pressure, dyspnoea, and quality of life to the performance in a walking distance test and a bicycle ergometer test was investigated.

Methods - Static lung volumes, forced expiratory volume in one second $\left(F E V_{1}\right)$, inspiratory slow vital capacity (IVC), transfer factor for carbon monoxide (TLCO) divided by the alveolar volume (TLCo/VA), static compliance (Cst), and maximal inspiratory peak pressure (PImaxPoEs) were measured in 40 patients with COPD with severe airways obstruction (mean FEV, 44\% predicted, mean $\mathrm{FEV}_{1} /$ IVC $37 \%$ predicted). Quality of life was assessed by the Chronic Respiratory Questionnaire (CRQ) and dyspnoea by the Borg category scale. Exercise capacity was measured by both a six minute walking distance (test) and a maximal work load of the bicycle ergometer test (Wmax).
\end{abstract}

Results - Spirometric values and maximal inspiratory pressure were modestly correlated with both the six minute walking test and $W \max , r$ values ranging from 0.50 to 0.58 . The TLCO was strongly correlated with the six minute walking test $(r=0.62)$ and with $W \max (r=0.78)$. Quality of life showed no correlation with exercise capacity, while there was a correlation between dyspnoea and the six minute walking test $(r=-0 \cdot 41)$. Backward linear regression analysis selected TLCO and PImaxPOES as the most significant determinants for exercise performance. They explained $54 \%$ and $69 \%$ of the variance in the six minute walking test and $W \max$, respectively.

Conclusions - The results show that exercise capacity in patients with COPD with severe airways obstruction is more strongly related to inspiratory muscle strength and lung function than to dyspnoea and quality of life. The significant correlation between dyspnoea and the six minute walking test suggests that subjec- tive variables are more strongly related to walking tests than to bicycle ergometer tests.

(Thorax 1994;49:468-472)

Patients with chronic obstructive pulmonary disease (COPD) usually have a decreased exercise tolerance and a reduced quality of life. While spirometric measurements seem to be related to maximum ventilation in a bicycle ergometer performance, ${ }^{1}$ in general they correlate weakly with less stressful tests such as the walking distance..$^{2-5}$ Moreover, it has been shown that the transfer factor for carbon monoxide (TLCO) is positively correlated with the walking distance test. ${ }^{67}$

Although dynamic and static lung volumes, compliance, and gas transfer (lung function) generally establish the level of impairment in COPD, Mahler and coworkers showed that maximal inspiratory pressure (MIP) provides additional information on impairment. ${ }^{8}$ Loiseau and coworkers ${ }^{9}$ also showed that exercise capacity in patients with COPD was related to the impairment of the inspiratory muscles. In addition, it has been shown in other studies that walking distance tests are related to psychosocial measurements, while no relation has been found between psychosocial measurements and bicycle ergometer tests. ${ }^{41011}$

Both objective and subjective measurements are related to exercise capacity in patients with COPD. However, we are not aware of any research on their relative effect on a walking distance test compared with a bicycle ergometer test. In this study we have therefore investigated the relative contribution of lung function, maximal inspiratory pressure, dyspnoea, and quality of life to the performance in a walking distance test as well as a bicycle ergometer test in patients with COPD.

\section{Methods}

PATIENTS

Forty patients with known COPD $^{12}$ (table 1) who started a rehabilitation programme were studied. Entry criteria were: (a) postbronchodilator $\mathrm{FEV}_{1}$ (forced expiratory volume in one second) $<60 \%$ predicted, and (2) postbronchodilator $\mathrm{FEV}_{1} / \mathrm{IVC}$ (inspiratory vital capacity) $<50 \%$ (after two inhalations of $40 \mu \mathrm{g}$ 
Table 1 Characteristics of 40 patients with COPD

\begin{tabular}{|c|c|c|c|}
\hline & \multicolumn{2}{|c|}{ Mean (SD) } & \multirow{2}{*}{$\begin{array}{l}\text { Range } \\
50-71\end{array}$} \\
\hline & $62 \cdot 4$ & $(5 \cdot 0)$ & \\
\hline FEV b (1) & 1.2 & $(0 \cdot 3)$ & $0 \cdot 6-1 \cdot 7$ \\
\hline FEV a (1) & $1 \cdot 3$ & $(0 \cdot 4)$ & $0 \cdot 7-1 \cdot 9$ \\
\hline FEV $_{1}$ (\%pred) & $44 \cdot 3$ & $(10 \cdot 6)$ & $26 \cdot 1-59 \cdot 1$ \\
\hline IVC (1) & 3.6 & $(0.9)$ & $2 \cdot 6-5 \cdot 4$ \\
\hline IVC (\%pred) & $91 \cdot 3$ & $(17 \cdot 2)$ & $53 \cdot 2-127 \cdot 1$ \\
\hline TLC (1) & $7 \cdot 6$ & $(1.5)$ & $4 \cdot 5-11 \cdot 3$ \\
\hline RV\%/TLC (\%pred) & 143.0 & $(25 \cdot 1)$ & $91 \cdot 2-169 \cdot 5$ \\
\hline TLCO $(\mathrm{mmol} / \mathrm{min} / \mathrm{kPa})$ & 6.5 & $(2.5)$ & $2 \cdot 2-11 \cdot 2$ \\
\hline TLCo $(\%$ pred $)$ & $74 \cdot 1$ & $(24 \cdot 5)$ & $21 \cdot 9-120 \cdot 7$ \\
\hline $\mathrm{T}_{\mathrm{LCO}} / \mathrm{VA}_{\mathrm{A}}(\mathrm{mmol} / \mathrm{min} / \mathrm{kPa} / \mathrm{l})$ & $1 \cdot 2$ & $(0.4)$ & $0.4-1 \cdot 8$ \\
\hline TLCO/VA (\%pred) & $70 \cdot 1$ & $(27 \cdot 4)$ & $23 \cdot 1-129 \cdot 3$ \\
\hline Cst $(1 / \mathrm{kPa})$ & 4.5 & $(3 \cdot 0)$ & $1 \cdot 6-17 \cdot 3$ \\
\hline PImaxPoEs (kPa) & $9 \cdot 5$ & $(2 \cdot 2)$ & $3 \cdot 9-15 \cdot 3$ \\
\hline
\end{tabular}

FEV $b=$ forced expiratory volume in one second before bronchodilation; $\mathrm{FEV}_{1} \mathrm{a}=\mathrm{FEV}_{1}$ after bronchodilation; \% pred $=\mathrm{ex}$ pressed as a percentage of the predicted value; $R V=$ residua volume; TLC = total lung capacity; TLCO = transfer factor for carbon monoxide; $\mathrm{VA}=$ alveolar volume; $\mathrm{Cst}=$ static lung compliance; PImaxPoEs = peak oesophageal pressure during a maximal semistatic manoeuvre.

ipratropium bromide). All patients showed severe airways obstruction (mean $\mathrm{FEV}_{1} 44 \%$ predicted, mean $\mathrm{FEV}_{1} /$ IVC $37 \%$ predicted) and little reversibility (mean increase in FEV of $0 \cdot 151$ ). They were admitted to hospital for two days in a clinically stable condition (no recent exacerbations). Patients with evidence of ischaemic heart disease, intermittent claudication, musculoskeletal disorders, or other disabling diseases that might restrict a rehabilitation programme were excluded. The study was approved by the medical ethics committee of the University Hospital of Groningen and all patients gave informed consent.

\section{STUDY DESIGN}

During the time in hospital the following measurements were carried out: (1) lung function, (2) maximal inspiratory pressure, (3) quality of life, (4) dyspnoea assessment, and (5) exercise capacity.

\section{Lung function}

On the first day total lung capacity (TLC), residual volume (RV), $\mathrm{FEV}_{1}$, IVC, diffusion capacity, volume-pressure relation, and static compliance were measured. Static lung volumes were determined in a constant volume whole body plethysmograph (Jaeger, Würzburg, Germany), and $\mathrm{FEV}_{1}$ and IVC were measured by means of a pneumotachograph (Jaeger, Würzburg, Germany). Transfer factor for carbon monoxide ( $\mathrm{TLCO}_{\mathrm{L}}$ ) and TLCO divided by alveolar volume (TLCO/VA) were measured by the single breath method. TLCO was corrected for the concentration of haemoglobin to obtain Tico under standard conditions using the method of Cotes. ${ }^{13}$ Volumepressure diagrams of the lungs were recorded using an oesophageal balloon and a spirometer. Static compliance was calculated from the volume-pressure diagram. Predicted values were derived from the ECCS. ${ }^{14}$

\section{Maximal inspiratory pressure}

Maximal inspiratory peak pressure was measured with a $10 \mathrm{~cm}$ balloon containing $0.5 \mathrm{ml}$ of air positioned in the middle of the oesophagus $40 \mathrm{~cm}$ away from the anterior nares. The balloon was connected to a pressure transducer (Hewlett Packard No.782018, Homburg, Germany) and the generated pressures were recorded. All patients were seated and wore a noseclip. Peak oesophageal pressure (PImaxPoes) was measured during a maximal semi-static inspiratory manoeuvre through an oval flanged mouthpiece. This manoeuvre was carried out at residual volume against a closed shutter with a small leak of $2.0 \mathrm{~mm}$ diameter to prevent the use of the buccinator muscles. ${ }^{15}$ It was performed at least five times with 20-30 seconds rest between each measurement. In all sessions the display in front of the patient provided visual feedback. Before each measurement the pressure transducer was calibrated with a Gambro Reference instrument, KO7046 (Gambro AB, Lund, Sweden) and ambient pressure was used as zero level.

\section{Quality of life}

Quality of life was assessed by the Chronic Respiratory Disease Questionnaire (CRQ). ${ }^{16}$ The questionnaire was translated into Dutch and administered on the first day before lung function and maximal inspiratory pressure were measured. The CRQ measures physical and emotional function divided into four dimensions: dyspnoea, fatigue, emotion, and mastery. The assessment of physical function includes asking patients to quantify their dyspnoea during five activities that are frequently performed and important in individual day to day life. Each patient was asked to choose five activities from a list of 25 or any activity that was not on the list. The dyspnoea dimension was therefore strictly individual. Physical function was also investigated by four items relating to fatigue and energy level. Assessment of emotional function, related to the dimensions of emotion and mastery, included questions about frustration, depression, anxiety, panic, and fear during dyspnoea. Patients were asked to rate their function on a seven point scale; for example 1 = "not tired at all," $7=$ "extremely tired." As the items underlying the dyspnoea dimension had a low internal consistency reliability we did not use this dimension in our study.

\section{Dyspnoea}

The level of dyspnoea at rest was assessed before both exercise tests by means of the Borg category scale. ${ }^{17}$

\section{Exercise capacity}

Six minute walking distance: on the first day the patients walked indoors as far as possible for a period of six minutes ${ }^{18}$ without encouragement. They had two training sessions to become familiar with the test.

Bicycle ergometer test: on the second day patients breathed through a mouthpiece and wore a noseclip during an incremental symptom limited bicycle ergometer test. Minute 
ventilation ( $\dot{\mathrm{VE}})$, oxygen uptake $\left(\dot{\mathrm{V}}_{2}\right)$, and carbon dioxide output $\left(\dot{\mathrm{V}}_{2}\right)$ were measured from analysis of the expirate every 30 seconds by a computerised system (EOS Sprint; Jaeger, Würzburg, Germany). Heart frequency was monitored simultaneously (Marquette Electronics, Milwaukee, USA) and arterial oxygen saturation $\left(\mathrm{SaO}_{2}\right)$ was recorded continuously by an ear oximeter (Biox IIA, Biox Technology, Colorado, USA). After one minute of unloaded pedalling, the work rate was increased by 10 watts $/ \mathrm{min}$. Patients were instructed to stop when they could not continue the test any longer because of dyspnoea or general fatigue. The maximal work load (Wmax) was defined as the highest work level reached and maintained for a full minute.

\section{STATISTICAL ANALYSIS}

The Kolmogorov-Smirnov test was used to compare distributions of the variables with standard normal distributions. The correlation between lung function, maximal inspiratory pressure, dyspnoea, and quality of life on the one hand, and exercise capacity on the other was investigated by means of the Pearson correlation coefficient $(r)$. Variables that showed a significant correlation $(\mathrm{p}<0.01)$ with either walking distance or maximal work load were used as independent variables in two multiple regression analyses. The six minute walking test and maximal workload were used as dependent variables. Because TLCO and TLCO/ VA are strongly related we used the variable with the highest correlation $(r)$ with exercise capacity in the regression analyses.

\section{Results}

The distributions of the variables did not significantly differ from a normal distribution. The mean dyspnoea score on the Borg scale at rest was $1 \cdot 6$, indicating slight breathlessness. The mean (SD) scores of the dimensions fatigue, emotion, and mastery were reduced, being $16 \cdot 2(5 \cdot 2)(57 \%$ of maximum score), 34.0 $(7 \cdot 1)(71 \%)$, and $20 \cdot 1(4 \cdot 7)(72 \%)$, respectively. Mean (SD) Wmax was 73.5 (33.1) watts, $\mathrm{SaO}_{2}$ decreased from $93.7(2 \cdot 0) \%$ at rest to 91.9 $(4.3) \%$ at Wmax, and mean walking distance was $448(103) \mathrm{m}$.

RELATION BETWEEN LUNG FUNCTION, MAXIMAL INSPIRATORY PEAK PRESSURE, DYSPNOEA, QUALITY OF LIFE, AND EXERCISE CAPACITY The six minute walking distance correlated significantly with Wmax of the bicycle ergometer test $(r=0.81, p<0.01)$. Lung function measurements and PImaxPoEs correlated significantly with maximal walking distance and Wmax on the bicycle ergometer (table 2). TLCo showed the highest correlation with both six minute walking distance and $\mathrm{Wmax}$ and was also significantly $(\mathrm{p}<0.001)$ correlated with both $\mathrm{FEV}_{1}$ and IVC $(r=0.72$ and 0.49 , respectively). In contrast, the fatigue, emotion, and mastery dimensions of the CRQ showed no significant correlation with exercise capa-
Table 2 Correlation coefficients of exercise capacity with lung function, maximal inspiratory pressure, dyspnoea, and quality of life

\begin{tabular}{|c|c|c|}
\hline & \multicolumn{2}{|c|}{ Exercise capacity } \\
\hline & $\begin{array}{l}\text { Walking test } \\
(\mathrm{m})\end{array}$ & $\begin{array}{l}\text { Maximal work } \\
\text { load (watt) }\end{array}$ \\
\hline $\operatorname{TLC}(1)$ & $0 \cdot 10$ & $0 \cdot 10$ \\
\hline RV (1) & $-0.41^{*}$ & $-0 \cdot 30$ \\
\hline FEV $_{1}(1)$ & $0.55^{* *}$ & $0.58^{* *}$ \\
\hline IVC (1) & $0.51^{*}$ & $0.50^{*}$ \\
\hline TLCO $(\mathrm{mmol} / \mathrm{min} / \mathrm{kPa})$ & $0.62^{* *}$ & $0 \cdot 78^{* *}$ \\
\hline $\mathrm{TLCO} / \mathrm{VA}(\mathrm{mmol} / \mathrm{min} / \mathrm{kPa} / \mathrm{l})$ & $0 \cdot 38^{*}$ & $0.53^{* *}$ \\
\hline Cst $(1 / \mathrm{kPa})$ & 0.02 & -0.09 \\
\hline PimaxPoes $(\mathrm{kPa})$ & $0.58^{* *}$ & $0 \cdot 54^{* *}$ \\
\hline Fatigue & -0.03 & -0.01 \\
\hline Emotion & -0.02 & -0.05 \\
\hline Mastery & -0.25 & $-0 \cdot 19$ \\
\hline Dyspnoea & $-0.41^{*}$ & $-0 \cdot 22$ \\
\hline
\end{tabular}

For definition of abbreviations see footnote to table 1

$* \mathrm{p}<0.01 ;{ }^{* *} \mathrm{p}<0.001$; values are the Pearson correlation coefficients $(r)$.

Fatigue, emotion, and mastery: sum scores of dimensions of the CRQ; dyspnoea: dyspnoea at rest scored on a Borg category scale.

city. Dyspnoea at rest as scored on the Borg scale showed a significant correlation $(\mathrm{p}<0.01)$ with the walking distance but not with Wmax on the bicycle ergometer.

In the first regression analysis we used the six minute walking distance as dependent variable and IVC, RV, FEV, TLCo, PImaxPoes, and dyspnoea as the independent variables. These six variables together explained $62 \%$ of the variance in six minute walking distance. However, the coefficients of $\mathrm{FEV}_{1}$, IVC, RV, and dyspnoea were not statistically significant. Consequently, the regression equation generated by backward stepwise multiple regression analysis for the six minute walking distance (6MD) included TLCo and PImaxPoEs (table 3):

$$
\begin{gathered}
6 \mathrm{MD}(\mathrm{m})=19 \cdot 7(\text { TLCO })+20 \cdot 2(\text { PImaxPoES }) \\
+121\left(r^{2}=0 \cdot 54\right) .
\end{gathered}
$$

Scatterplots of the distance walked in relation to TLCO and PimaxPoes are shown in fig $1 \mathrm{~A}$ and $1 \mathrm{~B}$, respectively.

In the second regression analysis we used Wmax as the dependent variable and IVC, $\mathrm{FEV}_{1}, \mathrm{TLCO}_{\mathrm{L}}$, and PImaxPoES as the independent variables. Similar to the equation for $6 \mathrm{MD}$, the regression equation generated by backward stepwise multiple regression analysis for Wmax included also TLCO and PimaxPoes (table 3):

$$
\begin{aligned}
\mathrm{Wmax}(\text { watt }) & =8 \cdot 1(\text { TLco })+4 \cdot 1 \text { (PImaxPoes }) \\
& -17 \cdot 7\left(r^{2}=0 \cdot 69\right) .
\end{aligned}
$$

Scatterplots of maximal work load in relation to Tlco and PImaxPoes are shown in fig $2 \mathrm{~A}$ and $2 \mathrm{~B}$, respectively.

\section{Discussion}

Stepwise regression analyses showed TLCO and PimaxPoes to be the only two significant determinants for exercise performance in a walking distance test and a bicycle ergometer test in patients with severe COPD. They explained $54 \%$ of the variance of the maximal walking distance and $69 \%$ of the maximal work load of the bicycle ergometer. 
Table 3 Multiple regression analysis showing the relative contribution of each of the variables to predict six minute walking test and maximal work load of the bicycle ergometer test

\begin{tabular}{|c|c|c|c|}
\hline & Cumulative $r^{2}$ & $\Delta r^{2}$ & F ratio \\
\hline $\begin{array}{l}\text { Six minute walking test: } \\
\text { TLCo } \\
\text { PImaxPoEs } \\
\text { FEV }_{1}, \text { IVC, RV, dyspnoea }\end{array}$ & $\begin{array}{l}0.39 \\
0.54 \\
0.62\end{array}$ & $\begin{array}{l}0.39 \\
0.15 \\
0.08\end{array}$ & $\begin{array}{r}20 \cdot 60^{* *} \\
17 \cdot 96^{* *} \\
7 \cdot 47^{* *}\end{array}$ \\
\hline $\begin{array}{l}\text { Maximal work load: } \\
\text { TLCo } \\
\text { PImaxPoES }_{\text {FEV }} \text {, IVC }\end{array}$ & $\begin{array}{l}0.61 \\
0.69 \\
0.69\end{array}$ & $\begin{array}{l}0.61 \\
0.08 \\
0.00\end{array}$ & $\begin{array}{l}50 \cdot 63^{* *} \\
33 \cdot 81^{* *} \\
15 \cdot 87^{* *}\end{array}$ \\
\hline
\end{tabular}

For definition of abbreviations see footnote to table 1 .

** $\mathrm{p}<0.001$. an oxygen desaturation during exercise. These factors are strongly interrelated, probably not in a linear way. The fact that in a multiple linear regression model TLCo explains a large part of the observed variance is merely an indication that the factors mentioned above are combined in a single number. As only a minor decrease in saturation during exercise occurred in our patients, a diffusion disorder was probably not the most important limiting factor. Patients in our study were mainly limited in their exercise capacity because they reached their maximal voluntary ventilation $\left(\mathrm{MVV}=37.5 \times \mathrm{FEV}_{1}\right)$.

Maximal inspiratory peak pressure (PImaxTLCo explained $39 \%$ of the variance in the six minute walking distance while it explained $61 \%$ of the variance in maximal work load. Other studies have shown that lower TLCO is associated with less exercise capacity in patients with airflow limitation. ${ }^{6719}$ Several factors may influence the single breath TLCO in COPD. Due to the breathing manoeuvre, impaired intrapulmonary gas mixing during the 10 second breath holding may lead to a low TLCO, as reflected by a difference between the measured VA with the single breath method and the plethysmographically determined TLC. Furthermore, airway collapse in these patients may provide a non-representative alveolar sample during the expiratory part of the manoeuvre. Increased dead space ventilation may also contribute to a decrease of TLCo. Finally, there is little doubt that the alveolar wall may be destroyed in these patients. Although TLCO is not usually significantly correlated with desaturation during exercise, ${ }^{720}$ this destruction of the alvolar wall leads to a "true" diffusion impairment, resulting in
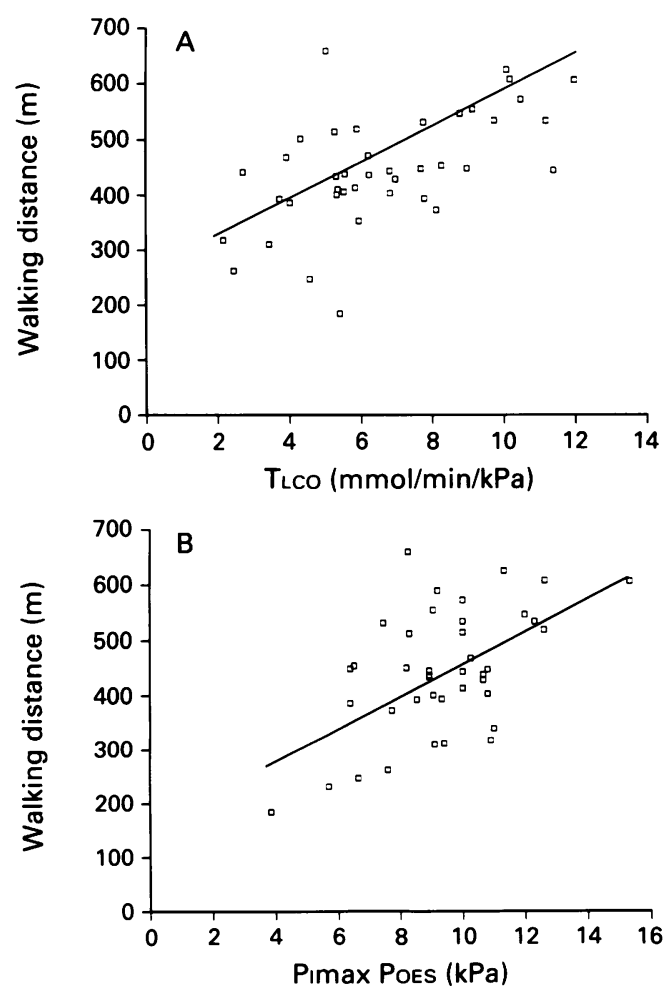

Figure 1 Scatterplots of six minute walking distance related $(A)$ to TLCO $(\mathrm{r}=0.62, p<0.001)$ and $(B)$ to PImaxPoes $(\mathrm{r}=0.58, p<0.001)$.

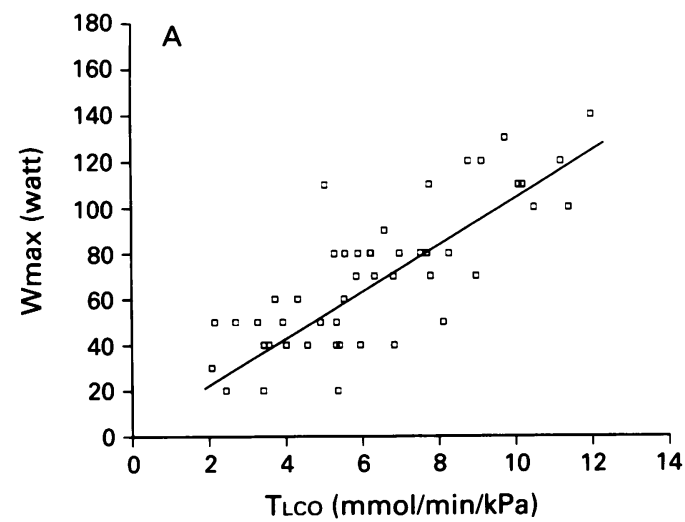

POES) also contributed significantly to the explanation of the variance of both six minute walking distance maximal work load. This result is in accordance with the study of Loiseau and coworkers ${ }^{9}$ who showed that exercise capacity in COPD was related to impairment of both active (inspiratory muscles) and passive (respiratory impedance) components of the ventilatory system. Our results are also compatible with the opinion that inspiratory muscle weakness may limit exercise tolerance in COPD. ${ }^{2122}$ Exercise capacity in patients with COPD with severe airways obstruction is apparently influenced by both inspiratory muscle strength and lung function impairment.

Several studies have investigated the relation between subjective measurements and exercise tolerance. Morgan et $a l^{4}$ found that depression and anxiety were correlated with the 12 minute walking distance. We had therefore expected that the fatigue, emotion, and

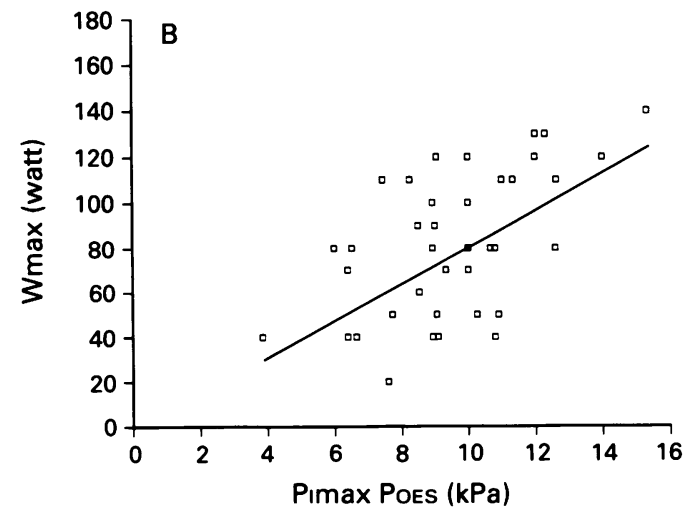

Figure 2 Scatterplots of maximal work load related PImaxPoes $(\mathrm{r}=0.54, p<0.001)$ (A) to TLCO $(\mathrm{r}=0.78, p<0.001)$ and $(B)$ to 
mastery dimensions of the CRQ would be correlated with the six minute walking distance. However, all three dimensions of the CRQ were neither correlated with the six minute walking distance nor with the maximal work load of the bicycle ergometer test. Our findings are in close agreement with those of Guyatt et al. ${ }^{16}$ The differences can be explained by the fact that Morgan included patients with a wider range of ventilatory impairment $\left(\mathrm{FEV}_{1}\right.$ 0.25-3.5 l, and FVC 1.1-5.2 l). Furthermore, Morgan and coworkers showed that attitudes and beliefs were of greater importance in predicting everyday exercise tolerance than disturbances of mood. Therefore, the patients' perception of their illness might have a more substantial effect on exercise capacity than fatigue, emotion, and mastery.

The relation between exercise capacity and subjective or objective measurements has been investigated in several studies. However, most have investigated only one aspect. The significance of our study is that we investigated the relation of both six minute walking distance and maximal work load with objective as well as subjective measurements in patients with COPD with severe airways obstruction. It is thus possible to assess the relative contribution of subjective and objective measurements to two different exercise tests in COPD.

Walking distance test and bicycle ergometer test measure different aspects of exercise capacity in patients with COPD, as suggested in several studies. ${ }^{1-31011}$ Unlike walking tests, performance in bicycle tests is limited by dyspnoea or leg fatigue. Moreover, the outcome with a bicycle ergometer test is thought to be better correlated with spirometric values. ${ }^{1-3}$ McGavin et al ${ }^{11}$ and Guyatt et $a l^{10}$ showed that subjective measures of disability correlate with the six minute walking distance, but not with maximal work load of the bicycle ergometer test. The results of our study seem to disagree with the above mentioned results by showing that both exercise tests were strongly related to the same objective variables - that is, TLCO and PimaxPoes. This may be partially explained by the fact that we found a highly significant relation between the six minute walking distance and maximal work load. TLCO and PImaxPoEs explained 15\% more of the variance in maximal work load than in the six minute walking test. Furthermore, we showed that dyspnoea at rest as assessed by the Borg scale correlated negatively with the six minute walking distance but did not correlate with maximal work load. Although the Borg scale may not be the most appropriate measurement for evaluating dyspnoea at rest, ${ }^{23}$ our results suggest that the two exercise tests measure different aspects of exercise limitation in COPD.

In summary, this study shows that maximal inspiratory peak pressure and TLCO are important variables in determining exercise capacity in patients with COPD with severe air- ways obstruction. Although dyspnoea at rest shows no significant correlation with the maximal work load of the bicycle ergometer test, it is significantly and negatively correlated with walking distance. This suggests that subjective measurements are better related to a walking test than to a bicycle ergometer test.

This study was supported by a grant of the Nederlands Astma Fonds (89.29) and the Foundation Astmabestrijding.

The authors wish to thank the lung function laboratory staff of Beatrixoord for their technical assistance in the performance of this study.

1 Carter R, Peavler M, Zinkgraf S, Fields S. Predicting maximal exercise in patients with chronic obstructive pulmonary disease. Chest 1987;92:253-9.

2 pulmonary disease. Chest 1987;92:253-9. Twelve minute walking test for assessing disability in chronic bronchitis. $B M \mathcal{F} 1976 ; 1: 822-3$.

3 Swinburn CR, Wakefield JM, Jones PW. Performance, ventilation and oxygen consumption in three different types of exercise tests in patients with chronic obstructive lung disease. Thorax 1985; 40: 581-6.

4 Morgan AD, Peck DF, Buchanan DR, McHardy GJR. Psychological factors contributing to disproportionate disability in chronic bronchitis. $\mathcal{F}$ Psychosom Res 1983;27: 259-63.

5 Mahler DA, Weinberg DH, Wells CK, Feinstein AR. Measurements of dyspnea. Contents, interobserver correlates of two new clinical indices. Chest 1984;85:751-8.

6 Mak VHF, Bugler JR, Roberts CM, Spiro SG. Effect of arterial oxygen desaturation on six minute walk distance, perceived effort, and perceived breathlessness in patients with airflow limitation. Thorax 1993;48:33-8.

7 Jones NL, Jones G, Edwards RHT. Exercise tolerance in chronic airway obstruction. Am Rev Respir Dis 1971;103: 447-91.

8 Mahler DA and Harver A. A factor analysis of dyspnea ratings, respiratory muscle strength, and lung function in patients with chronic obstructive pulmonary disease. $\mathrm{Am}$ Rev Respir Dis 1982;145:467-70.

9 Loiseau A, Dubreuil C, Loiseau P, Pujet JC, Georges R, Saumon G. Exercise tolerance in chronic pulmonary disease; importance of active and passive components of the ventilatory system. Eur Respir $\mathcal{F}$ 1989;2:522-7.

10 Guyatt GH, Thompson PJ, Berman LB, Sullivan MJ, Townsend $M$, Jones NL, et al. How should we measure function in patients with chronic lung disease. 7 Chronic function in patients
Dis $1985 ; 38: 517-24$.

11 McGavin CR, Artvinli M, Naoe H, McHardy GJR. Dyspnea, disability and distance walked: comparison of estimates of exercise performance in respiratory disease. $B M \mathcal{1} 1978 ; 2: 241-3$.

12 Standards for the diagnosis and care of patients with chronic obstructive pulmonary disease (COPD) and asthma. An official statement of the American Thoracic Society. Am Rev Respir Dis 1987;136:225-44.

13 Cotes JE. Lung function: assessment and application in medicine. 4th edn. Oxford: Blackwell Scientific, 1979.

14 Quanjer PH, ed. Standardized lung function testing. Report of Working Party on Standardization of Lung Function Tests. European Community for Coal and Steel, Luxem-

15 Black LF, Hyatt RE. Maximal respiratory pressure: norma values and relationship to age and sex. Am Rev Respir Dis values and relation $1969 ; 99: 696-702$.

16 Guyatt GH, Berman LB, Townsend M, Pugsley SO, Chambers LW. A measure of quality of life for clinical trials in chronic lung disease. Thorax 1987;42:773-8

17 Borg G. Psychophysical bases of perceived exertion. Med Sci Sports Exerc 1982;5:377-81.

18 Butland RJA, Pang J, Gross ER, Woodcock AA, Geddes DM. Two-, and six- and 12 minute walking tests in respiratory disease. $\mathrm{Br} \mathcal{f}$ Dis Chest 1982;284:1607-8.

19 O'Reilly JF, Shaylor JM, Fromings KM, Harrison BDW. The use of the 12 minute walking test in assessing the effect of oral steroid therapy in patients with chronic airways obstruction. Br $\mathcal{F}$ Dis Chest 1982;76:374-82.

20 Owens GR, Rogers RM, Pennock BE, Levin D. The diffusing capacity as a predictor of arterial oxygen desaturation during exercise in patients with chronic obstructive pulmonary disease. $N$ Engl $f$ Med obstructive pulm
1984;310:1218-21.

21 Dekhuijzen PNR, Folgering HT, van Herwaarden CL. Target-flow inspiratory muscle training during pulmonary rehabilitation in patients with COPD. Chest 1991;99. 128-33.

22 Folgering $H$, Dekhuijzen $R$, Cox $N$, van Herwaarden $C$ The rationale of pulmonary rehabilitation. Eur Respir Rev 1991;1:6,464-71.

23 Eakin EG, Kaplan RM, Ries AL. Measurement of dyspnoea in chronic obstructive pulmonary disease. Quality of Life Res 1993;2:181-91. 